\title{
LA JUSTICIA RESTAURATIVA EN EL SISTEMA PENAL JUVENIL: Las Experiencias de Brasil y Chile
}

\author{
http://dx.doi.org/10.21527/2176-6622.2020.53.221-232
}

Recebido em: 21/12/2019

Modificações solicitadas em: 14/4/2020

Aceito em: 20/4/2020

Rodrigo Cristiano Diehl

Alumno de Doctorado en Derecho por la Universidad de Santa Cruz do Sul con orientación conjunta del Programa de Posgrado en Ciencias Políticas de la Universidad Federal de Rio Grande do Sul, con beca Capes. Master en Política Social y Trabajo Social de la Universidad Federal de Rio Grande do Sul. Master en Derecho de la Universidad de Santa Cruz do Sul, con beca Capes. Profesor universitario y abogado. http:// lattes.cnpq.br/02848. http://orcid.org/0000-0002-4869-3112. rodrigocristianodiehl@live.com

\section{Rosane Teresinha Carvalho Porto}

Estudiante de postdoctorado en Derecho en la Universidad La Salle. Doctora y Master en Derecho por la Universidad de Santa Cruz do Sul, en el área de concentración: Políticas Públicas de Inclusión Social con beca de la Coordinación para el Mejoramiento del Personal de Educación Superior - Capes. Profesora de la Universidad Regional del Noroeste del Estado de Rio Grande do Sul - Unijuí, docente de pregrado en Derecho y Programa de Postgrado en Derecho - Máster y Doctorado. Profesora de Derecho en la Universidad de Santa Cruz do Sul. Estudia temas centrados en niños y adolescentes, violencia, criminología, géne-
ro, derechos sociales, acceso a la justicia y derechos humanos. http://lattes.cnpq.br/4041974927424063. https://orcid.org/0000-0002-0391-9341. rosaneporto@unisc.br

Bianca Baracho

Master en Psicología, con mención en Psicología Comunitaria de la Universidad de Chile (2018). Licenciado en Derecho por la Universidad de Fortaleza (2014). Estudia especialización en Mediación en Conflictos Sociales y Ambientales en el Centro de Políticas Públicas de la Pontificia Universidad Católica de Chile (2019). Investigadora y Coordinadora Asistente del Programa de Justicia Restaurativa y Paz Social en la Escuela de Trabajo Social de la Pontificia Universidad Católica de Chile. https://orcid.org/0000-0002-82620048. bbaracho@uc.cllattes

\section{RESUMEN}

La Justicia Restaurativa permite una nueva mirada a la pacificación de los conflictos y la armonización de las relaciones sociales. Con este fin, el presente estudio tiene como objetivo analizar cómo ocurre el proceso de implementación de las prácticas de Justicia Restaurativa juvenil en Brasil y Chile y cómo las políticas públicas y el sistema de justicia penal juvenil de cada país facilitan y/o dificulta este proceso. Para lograr este objetivo, se hacen la siguiente pregunta: ¿cuáles son los procesos sociales, políticos y económicos que facilitan y/u obstaculizan la implementación de prácticas de Justicia Restaurativa juvenil en Brasil y Chile como políticas públicas que forman parte del sistema de justicia? El estudio, desarrollado a través de un método de enfoque deductivo y la búsqueda documental y bibliográfica como técnica de investigación, se estructura en tres momentos: en el primero, describe un panorama de la Justicia Restaurativa juvenil en Brasil, en el segundo momento, trae a la discusión la realidad de la Justicia Restaurativa juvenil en Chile y, en el tercer subcapítulo, hace algunas consideraciones comparativas entre los dos modelos. Los resultados muestran cómo cada país implementa programas de Justicia Restaurativa juvenil en escenarios legales cercanos pero diferentes. Aunque Brasil y Chile tienen, en cierta medida, sistemas jurídicos e instituciones jurídicas sólidos, la aplicación de la Justicia Restaurativa debe concebirse y analizarse como una posibilidad de modernizar la comprensión y las formas de abordar los conflictos.

Palabras-clave: Brasil. Chile. Justicia restaurativa. Sistema penal juvenil.

\section{A JUSTIÇA RESTAURATIVA NO SISTEMA PENAL JUVENIL: AS EXPERIÊNCIAS DO BRASIL E DO CHILE}

\section{RESUMO}

A Justiça Restaurativa possibilita um novo olhar em relação a pacificação dos conflitos e a harmonização das relações sociais. Sob esse intuito, o presente estudo tem por objetivo analisar como ocorre o processo de implementação das práticas de Justiça Restaurativa Juvenil no Brasil e no Chile e como as políticas públicas e o sistema de justiça penal juvenil de cada país facilita e/ou obstaculiza esse processo. Para atingir tal objetivo, questiona-se sobre a seguinte problemática: quais os processos sociais, políticos e econômicos que facilitam e/ou obstaculizam a implementação das práticas de Justiça Restaurativa Juvenil no Brasil e no Chile enquanto políticas públicas integrantes do sistema de justiça? 0 estudo, desenvolvimento por meio método de abordagem dedutivo e da busca documental e bibliográfica enquanto técnica de pesquisa, está estruturado em três momentos: no primeiro, traça um panorama da Justiça Restaurativa juvenil no Brasil, no segundo momento, traz à discussão a realidade da Justiça Restaurativa juvenil no Chile e, no terceiro subcapítulo, realiza algumas considerações comparativas entre os dois modelos. Os achados mostram a forma em que cada país implementa os programas de Justiça Restaurativa juvenil sob cenários jurídicos próximo, porém, diferentes. Mesmo que Brasil e Chile possuem, de um certo modo, ordenamentos jurídicos e instituições jurídicas sólidas, a aplicação da Justiça Restaurativa deve ser concebida e analisada como uma possibilidade de modernização do entendimento e das maneiras de lidar com os conflitos.

Palavras-chave: Brasil. Chile. Justiça restaurativa. Sistema penal juvenil.

\section{SUMÁRIO}

1 Introducción. 2 Justicia restaurativa juvenil en Brasil. 3 La justicia penal juvenil en Chile. 4 Brasil y Chile juntos en la justicia juvenil: posibles diálogos. 5 Conclusiones. 6 Referencias. 


\section{INTRODUCCIÓN}

Si bien la Justicia Restaurativa (JR) no tiene un concepto único y puede ser entendida cómo un paradigma, una teoría, o un conjunto de procesos y resultados. La Organización de las Naciones Unidas (ONU , 2006, p. 6) la define como "una metodología para solucionar problemas que, de varias maneras, involucra a la víctima, al ofensor/a, las instituciones judiciales y la comunidad". Es destacable su enfoque orientado a reparar, en la medida de lo posible, el daño causado por el crimen u otras trasgresiones, posicionando como elemento central la participación activa de los principales afectados - la víctima, del ofensor y a menudo de otras partes (la comunidad) - en la resolución del conflicto - identificación del daño causado y en el diseño de alternativas para la repararlo.

En el contexto internacional, su regulación fue: por los actos del Consejo Económico y Social (CES) de las Organizaciones de las Naciones Unidas (ONU): Resolución CES/UN 1.999/26, de 28 de julio de 1999: que prevé la "Preparación y aplicación de la justicia restaurativa y medidas de mediación en materia de justicia penal"; Resolución CES/ONU 2000/14 de 27 de julio de 2000: "Principios básicos sobre el uso de programas de Justicia Restaurativa en materia penal". ONU No. 2.002/12, 24 de julio de 2002: luego definió "Principios básicos para el uso de programas de Justicia Restaurativa en asuntos penales" (FLORES; ROLIANO, 2016).

Dentro de la justicia juvenil, la JR es especialmente valorada debido a la consistencia entre sus objetivos, y la llamada justicia restaurativa juvenil (JRJ) ha protagonizado importantes reformas legales y procesales en varios países del mundo. ${ }^{1}$ Compartiendo principios y valores presentes en diversos instrumentos internacionales que refieren a infancia y justicia juvenil, responde a la demanda por un sistema especializado centrado en la reinserción social, sumándose a la necesidad de la desjudicialización, la restricción de la privación de libertad y de enfatizar el rol de la familia, fomentando la dignidad y responsabilización del joven: Convención sobre los Derechos del Niño/a (1989); Las Reglas de Beijing (1985); Directrices de Riad (1990); Reglas de La Habana (1990); Reglas de Viena (1997).

Especialmente en Latinoamérica, aunque no existen normas concretas relacionadas con la JRJ, existen documentos orientadores latinoamericanos que no son vinculantes, pero expresan principalmente la voluntad de los expertos reunidos en diferentes encuentros vinculados a la temática, como: Carta de Araçatuba (2005), Carta de Recife (2006), Declaración de Costa Rica sobre la Justicia Restaurativa en Latinoamérica (2005) y Declaración de Lima sobre Justicia Restaurativa Juvenil (2009).

En las últimas décadas, varios países de Latinoamérica han comenzado a integrar elementos innovadores en su intervención los cuales, sin abandonar los principios rectores de los sistemas retributivos, han dado espacio a procesos menos formales que responden a mecanismos propios de la JR (BOLÍVAR et al., 2017). Esa diseminación de las practicas restaurativas en la región presenta una diversidad de prácticas que van desde experiencias institucionalizadas, en ocasiones con legislaciones propias, a prácticas informales, y en general responde a una necesidad de reforma que se propone a responder a una gama de necesidades y realidades del continente las cuales, considerando su particular escenario sociocultural, parecen relacionarse con una estrategia para enfrentar a problemas específicos: la necesidad de bajar las poblaciones carcelarias, aumentar la transparencia en la administración de justicia y aliviar la sobrecarga en el sistema judicial.

Con el fin de contribuir con los actuales debates acerca de estos innovadores mecanismos de justicia en Latinoamérica, la idea de fondo de este artículo es ofrecer un marco referencia para apoyar los procesos restaurativos en el contexto penal juvenil latinoamericano, rescatando las experiencias de Brasil y Chile. Este articulo tiene como objetivo analizar cómo se implementan las prácticas de JRJ en Brasil y Chile, y cómo las políticas públicas y el sistema de justicia penal juvenil de cada país facilitan y/u obstaculizan este proceso.

La metodología utilizada será el método de enfoque deductivo y, como técnica de investigación, el documental y el bibliográfico. El texto está dividido en tres partes: la primera presenta el tema relacionado con la Justicia Restaurativa juvenil en Brasil que trata sobre el Estatuto del Niño y del Adolescente, así como la Ley de Sinase en el sistema penal juvenil, además de la implementación de prácticas restaurativas en el contexto juvenil. En segundo lugar, la justicia penal juvenil en Chile, abordando el proceso de implementación de prácticas restaurativas a través del análisis y los avances necesarios de la Ley de Responsabilidad Penal Juvenil y el

Ver más en: Dunkel, Horsfield y Parosanu (2015). 
proyecto de ley actual que crea el nuevo Servicio Nacional para la Reinserción Social Juvenil y; en tercer lugar, la problematización de los problemas fundamentales de la implementación de la Justicia Restaurativa en el sistema de justicia penal juvenil, analizando los procesos que facilitan/dificultan su implementación en Brasil y Chile.

En este contexto, la pregunta es: ¿cuáles son los procesos sociales, políticos y económicos que facilitan y/u obstaculizan la implementación de prácticas de justicia restaurativa juvenil en Brasil y Chile como políticas públicas que forman parte del sistema de justicia?

\section{JUSTICIA RESTAURATIVA JUVENIL EN BRASIL}

El Estatuto de Niños y Adolescentes (Ley 8.069/90) y Sinase (Sistema Nacional de Asistencia Socioeducativa - Ley N. 12.594/2012) son las principales políticas protectoras y socioeducativas dirigidas a niños y adolescentes, ya sea que sean autores de una infracción o víctimas de violaciones de los derechos fundamentales que también figuran en la Constitución Federal de 1988. Para este fin, estos principios son instrumentos legales y de protección para todos los niños y adolescentes, considerados en Brasil como sujetos de derechos. Es importante mencionar que para la legislación estatutaria se considera niño de cero a 12 años incompletos y adolescente, de 12 años completos hasta alcanzar la edad penal (18 años).

A pesar de mencionar, el adolescente en conflicto con la ley, es decir, quien comete una infracción debe ser considerado responsable de acuerdo con las medidas socioeducativas previstas en el artículo 112 del Estatuto del Niño y del Adolescente, sin responder penalmente, pero sí ante los tribunales especializados, llamados de Tribunal de Niños y Jóvenes. Sin embargo, debido a que están infringiendo actos análogos a los tipos criminales descritos en el Código Penal; su responsabilidad guiada por el propio Estatuto y dando lugar a la ejecución por la política socioeducativa de Sinase, no debe ignorarse que estos también son asuntos relacionados con el sistema penal juvenil. Este sistema, consolidado y compuesto por recomendaciones y regulaciones internacionales, como las Reglas de Beijing (1985), entre otras.

Debido a esto, existe la Ley del Sinase (Sistema Nacional de Asistencia Socioeducativa - Ley 12.594/12) que, además del enfoque socioeducativo para la ejecución y el cumplimiento de las medidas socioeducativas por parte del autor adolescente de un delito, recibe en su cuerpo las prácticas restaurativas.

En el contexto de la política socioeducativa, el Estado brasileño tiene una legislación específica que conforma este sistema. Estos son marcos normativos que formulan la atención socioeducativa en el país, desde la Constitución Federal de 1988 y continuaron en la regulación de las políticas de la infancia, desde el Estatuto de Niños, Niñas y Adolescentes. Este último estructura las bases para el desarrollo de la Protección Integral para Niños y Adolescentes y para la construcción de la implementación de políticas públicas en Brasil.

Bucci $(2006$, p. 39) conceptualiza la política pública como una especie de "[...] programa de ação governamental que resulta de um processo ou conjunto de processos juridicamente regulados". Es decir, las políticas públicas se basan en el surgimiento de demandas sociales que requieren atención y apoyo del poder público.

El Estatuto establece, por primera vez, el sistema de atención a adolescentes que cometieron una infracción como medidas socioeducativas. El modelo de servicio se describe en la Resolución no. 119/2006 del Consejo Nacional para los Derechos de Niños, Niñas y Adolescentes (Conanda), que estableció el Sinase en todo el país. Posteriormente, la Ley Federal no. 12.594/2012 confirmó el Sinase. Además, existe la Resolución $\mathrm{N}^{\circ} 160$ de Conanda que promulgó el Plan Nacional de Asistencia Social y Educativa, con objetivos para la red de servicios y el sistema de justicia entre 2013 y 2023.

La legislación legal define en el artículo 103 para un delito "a conduta descrita como crime ou contravenção penal" cometida por un adolescente y establece, en el artículo 112, la aplicación de seis tipos de medidas socioeducativas: advertencia, obligación de reparar el daño, prestación de servicios a la comunidad, libertad asistida, inserción en régimen de semi-libertad e internación en establecimientos educativos.

Los datos de la Encuesta Anual Sinase (2016) del Ministerio de Derechos Humanos indican un número total de 25.929 (veinticinco mil novecientos veintinueve) adolescentes y jóvenes (de 12 a 21 años) en atención socioeducativa en las unidades centradas en la restricción y la privación de libertad (internamiento, detención provisional y semi-libertad), además de 521 (quinientos veintiuno) adolescentes en otras modalidades de atención (atención inicial, hospitalización por sanción), con un total de 26.450 (veintiséis mil cuatrocientos 
cincuenta ) adolescentes y jóvenes incluidos en el sistema. En atención social y educativa abierta (servicio comunitario y libertad asistida), el Ministerio de Desarrollo Social (2018) indica un número de 117,207 adolescentes y jóvenes que cumplen con tales medidas. Esta cantidad representa el $78 \%$ de todas las medidas socioeducativas aplicadas en Brasil, y las medidas de semi-libertad y hospitalización se incluyen en el $22 \%$ restante. Brasil cuenta con un total de 477 unidades de privación, la mayoría de las cuales están dedicadas exclusivamente a adolescentes varones (87\%) (RAMIDOFF, 2012).

La calificación de la atención socioeducativa es un desafío que se debe enfrentar de manera intersectorial, con base en las normas establecidas por la legislación legal y en la prioridad absoluta de la infancia y la adolescencia. La confrontación del sistema socioeducativo a enfrentar con respecto al hacinamiento de las unidades, la muerte de adolescentes durante el cumplimiento de las medidas socioeducativas, la brecha escolar, la distorsión por grado de edad, la ausencia de proyectos de formación profesional, la pérdida de lazos familiares y comunitarios, la falta de diagnósticos sobre la aplicación de medidas sociales y educativas, la vulnerabilidad de adolescentes y jóvenes y la necesidad de fortalecer las medidas sociales y educativas en el entorno abierto.

Al considerarse un marco teórico y legal para la implementación de la Justicia Restaurativa, a través de las prácticas metodológicas en el sistema penal juvenil, este cambio paradigmático se debe a la reforma del poder judicial a mediados de los 90 , con la búsqueda de mecanismos de acceso a la justicia y las metodologías participativas. Por lo tanto, la crisis judicial precedió a la implementación de las prácticas restaurativas.

En 2004 y 2005 comenzó el camino de la Justicia Restaurativa en Brasil, con el Ministerio de Justicia (MJ) a través de su Secretaría de Reforma Judicial (SRJ), implementando el proyecto "Promoción de prácticas restaurativas en el sistema de justicia brasileño", financiado por el Programa de las Naciones Unidas para el Desarrollo - PNUD, y se implementó en tres proyectos piloto sobre prácticas restaurativas en Porto Alegre (RS), São Caetano (SP) y Brasilia (DF), todos vinculados al Poder Judiciario (FLORES; ROLIANO, 2016).

El tema de la Justicia Restaurativa se ha vuelto muy recurrente en los tribunales brasileños, desde la aprobación por el Consejo Nacional de Justicia de la Resolución 225 de 2016, que establece la política nacional de Justicia Restaurativa dentro del poder judiciario. Aunque este acto normativo no tiene fuerza de ley, ofrece a los magistrados y a la comunidad algunas nociones sobre el tema, sus principios y procedimientos, y proporciona pautas sobre cómo desarrollar proyectos de justicia restaurativa con los Tribunales de Justicia (ACHUTTI; PALLAMOLLA, 2017).

Se observa que los programas, proyectos y acciones en Justicia Restaurativa son, por regla general, coordinados y promovidos por el Poder Judicial, con la gestión de las iniciativas, sin embargo, son áreas no necesariamente dedicadas exclusivamente a tales actividades, con un enfoque prioritario en otras áreas, como los Nupemec (Centro Permanente para Métodos de Resolución Consensual de Conflictos), Presidencias, Coordinación de la Infancia, entre otros. Como resultado, por ejemplo, la gran mayoría de los programas, proyectos o acciones en Justicia Restaurativa no tienen un personal dedicado o un espacio exclusivo para llevar a cabo sus prácticas, y a menudo usan espacios de otros sectores como Cejuscs (Centro Judicial para la Resolución de Conflictos y Ciudadanía), o incluso fuera del Poder Judicial.

Las metodologías restaurativas más utilizadas o de interés son las prácticas circulares, ya sean los círculos de construcción de paz de Kay Pranis y aquellos basados en la comunicación no violenta. La mayoría de los programas, proyectos o acciones se centran en conflictos relacionados con la infancia y la juventud (Justicia Restaurativa juvenil), delitos menores y violencia doméstica, aunque hay un gran interés en el desarrollo de capacidades y acciones restaurativas en el derecho de familia (BRASIL, 2019).

En términos conceptuales sobre lo que es la Justicia Restaurativa y las prácticas, se están discutiendo y consolidando en Brasil, teniendo como parámetro la Resolución 225 de 2016 del Consejo Nacional de Justicia y la Ley no. 12.594/12 (Sinase). Importante mencionar que la referida Ley, correlacionada con la Ley 8.069/1990 (Estatuto del Niño y del Adolescente), incluso recibiendo en su artículo 35, III de Sinase, las prácticas restaurativas, demuestra que el legislador brasileño tenía la preocupación de prever en el Sistema Principios constitucionales socioeducativos brasileños, que detallan la implementación de medidas socioeducativas, creando lagunas y dificultades en la operacionalización de las medidas socioeducativas; entre ellos: qué hacer y cómo hacer con las prácticas restaurativas en la implementación de medidas socioeducativas (MELO NETO, 2019). 
El enfoque restaurativo dado por la Resolución 225 del CNJ llenó los vacíos legales/normativos, ${ }^{2}$ dejando al Estado y a la sociedad tener la voluntad política y social para llevar a cabo, para guiar soluciones pacíficas de resolución de conflictos. La Justicia conocida como una filosofía de vida o la justicia de valores, principios y la comunidad llegó a Brasil con su curso institucionalizado por el Poder Judicial. En términos de marco teórico, sus principales autores fueron: Howard Zehr y Kay Pranis. Al revisarlos, uno nota el protagonismo no de la ciencia, sino de los actores que emergen de los paseos empíricos, causando en sus acciones el impacto social. Zehr (2008) habla de la necesidad de un cambio de paradigma, la forma de percibir y ver las cosas. En otras palabras, ¿pensar qué es la justicia? Y cómo ponerlo en práctica de manera diferente a lo que se ha hecho y producido hoy.

Para Pranis (2010), la metodología utilizada para pensar y vivir en equilibrio y justicia responsable es a través del proceso circular. El proceso de círculo es un proceso que tiene lugar a través de la narración de historias. Cada persona tiene una historia y cada historia ofrece una lección. En el Círculo, las personas se acercan compartiendo historias significativas para ellos.

En Brasil, entre las prácticas de Justicia Restaurativa más diversas, hay los círculos de construcción de paz de Kay Pranis. La propuesta del proceso circular ha sido aceptada, sobre todo, en proyectos que involucran escuelas. La adopción de esta metodología en Justicia Restaurativa es un hito simbólico y de muchas resignificaciones en el campo epistemológico. De las experiencias brasileñas con esta práctica, queda claro que los involucrados (víctimas, delincuentes y comunidad) se identifican y se abren al diálogo y a la construcción de una forma prospectiva de pacificar los conflictos. Los círculos de construcción de paz de Kay son una técnica o herramienta de prospección potencial dentro de las políticas públicas judiciales y extrajudiciales.

Además, podemos ver los avances de la Justicia Restaurativa en diferentes contextos, como el Estado, las comunidades, las escuelas, entre otros, como asociaciones creadas junto con el Poder Judicial brasileño. Lo que sucede es que las prácticas restaurativas surgieron de debates y discusiones con profesionales, voluntarios que se unieron formando un movimiento social incipiente para repensar las estrategias para enfrentar conflictos en áreas más específicas como: niños y adolescentes. Por lo tanto, después de conocer la realidad y las regulaciones brasileñas, es relevante conocer la justicia penal juvenil en Chile. Este tema se trata en el siguiente tema.

\section{LA JUSTICIA PENAL JUVENIL EN CHILE}

Con la ratificación y vigencia en Chile de la Convención sobre los Derechos del Niño, Niña y Adolescente en 1990, la Ley de Responsabilidad Penal Adolescente (LRPA), № 20.084 de 2007, es el principal avance a nivel legislativo en el contexto de la justicia juvenil nacional, aplicado para todos los adolescentes entre 14 y 18 años que han cometido un delito. Apunta a "hacer efectiva la responsabilidad de los adolescentes por los hechos delictivos que cometan, de tal manera que la sanción forme parte de una intervención socioeducativa amplia y orientada a la plena integración social" (Ley 20.084, artigo 20; énfasis añadido).

En ese sentido, el enfoque de la intervención es la responsabilización de los jóvenes infractores, la reinserción social y la prevención de la reincidencia, incorporando nuevas estrategias de "diversificación" de las respuestas estatales como las salidas alternativas, y también a través de sanciones no privativas de libertad (nuevas sanciones de contenido reparatorio, como penas de reparación a la víctima y los servicios en beneficio de la comunidad) (DÍAZ, 2010), priorizando un contacto mínimo o reducido de los adolescentes con la justicia criminal y se aplica la privación de libertad como último recurso (BERRÍOS, 2011; BOLÍVAR et al., 2017; DE LA MAZA, 2013).

Si bien los procesos de delitos juvenil son juzgados en los mismos tribunales donde también actúan casos de adultos, todos a cargo de los Ilamados Tribunales de Garantía, la ley garantiza una sala especializada para eses tipo de causa, con un abogado defensor juvenil especializado, y también un fiscal especializado. Según establece la LRPA, cabe al fiscal recolectar evidencias del delito y al defensor reducir la sanción, ignorando dentro del contexto del proceso judicial otros elementos psicosociales relevantes del joven, los cuales

\footnotetext{
Por lagunas normativas, se refiere a la inexactitud de los contenidos legales de ciertos institutos de ECA que permanecen abiertos, sin que la doctrina o la práctica hayan construido una interpretación clara y delimitada, basada en la Doctrina de Protección Integral.
} 
pueden ser solicitados con excepcionalidad por el juez (a través de una evaluación de un equipo especializado, una práctica poco presente en los Juzgados de Garantía) (REYES, LABRENZ, DONOSO, 2018). En ese sentido, las sanciones penales se relacionan íntimamente con criterios usados en el sistema penal de adultos, como el nivel de gravedad del delito y pasaje anterior en el sistema penal, en un tono más persecutorio y punitivo, distanciándose de las necesidades psicosociales del adolescente (REYES; LABRENZ; DONOSO, 2018).

En concreto, el análisis acerca la implementación de la ley no ha sido positiva, apuntando al no cumplimento de su objetivo y la inefectividad de ciertas sanciones, centrándose más en la individualización de la culpa y se distanciando del carácter "restaurativo", con graves falencias en el diseño y aplicación de algunas sanciones, como el Boletín n S 1.555-14 (CHILE, 2012) y Comité de Evaluación (OCDE, 2015): la sentencia condenatoria es la salida más habitual para jóvenes y, a pesar de la disminución del uso de la privación de libertad, hubo un aumento importante en la duración de las condenas de privación de libertad (BERRíOS, 2011). Evaluada en distintos momentos, distintas comisiones e instituciones relatan que la implementación de la Ley no ha sido prioridad del Estado, con escasa coordinación entre el sistema de intervención y el sistema legal, destacándose (MIRANDA et al., 2018): la falta de especialización y capacitación de los profesionales en materia infantojuvenil; y la falta de condiciones y ofertas programáticas en los recintos que están a cargo de implementar las sanciones, a través del llamado Servicio Nacional de Menores (Sename), sobre la gestión del Estado. $^{3}$

Sobre la Política de Infancia que adopta el Estado de Chile, es muy controversial en el trato y cuidado con sus niños, niñas y adolescentes, ya que carece de una legislación de protección integral a la infancia, pero, por otro lado, concretizó una LRPA; mejor diciendo, interviene solamente cuando se presenta una situación de vulneración o de irregularidad, desde donde el Fondo de las Naciones Unidas para la Infancia en la Agenda de Infancia 2018-2021 establece el principal desafío de Chile: la creación de un Sistema de Protección Integral de Derechos de la Niñez (MIRANDA et al., 2018).

Por otro lado, frente a las deficiencias del Estado, y en el sentido de ratificar su compromiso con la CDN se presentan diversos proyectos ley: en 2015 se presentó la propuesta que trata del Sistema de Garantías de los Derechos de la Niñez, en el sentido de proteger y garantir de manera integral el ejercicio efectivo y el goce pleno de los derechos de los niños y, específicamente en el contexto penal juvenil, en 2017 se presentó el proyecto de ley que crea el nuevo Servicio Nacional de Reinserción Social Juvenil (SNRSJ), ambos en tramitación actualmente.

El Sistema de Garantías de los Derechos de la Niñez está pautado en principios como de la autonomía progresiva y del interés superior del niño, y establece como orientadores de las políticas de Estado la participación y el derecho a ser oído, abriendo espacio para reformar aspectos problemáticos en el sistema penal juvenil (BOLÍVAR et al., 2017). En ese contexto, y esencialmente a la LRPA, el nuevo SNRSJ propone una reforma no solo desde un punto de vista procesal, sino que también estructural, diseñando una política consistente de reinserción social y un servicio descentralizado, que asume un carácter pionero en el país. Contempla un modelo de intervención basado en los principios de la Justicia Restaurativa (JR), entre otras perspectivas teóricas, y propone la creación de un Programa de Mediación Penal como medida de diversificación y nueva vía de alternatividad al proceso, proyectando una mejora en la calidad de la respuesta estatal al conflicto (Boletín 11174-07).

En concreto, asumiendo la JR como un enfoque teórico y una metodología que ha sido validado por la evidencia, Chile está comenzando a integrarse en el desafío de incorporar la JR en la compresión del conflicto penal y los procesos de reinserción social de sus jóvenes, pero respondiendo también a los derechos y necesidades de las víctimas. Dicha iniciativa nacional responde a la recomendación de organismos internacionales y regionales acerca la inclusión de la JR en los procedimientos penales, especialmente en justicia juvenil, ${ }^{4}$ y además está en consonancia con la Política Nacional de Víctimas que, respondiendo a normativas regionales

\footnotetext{
Con relación a las sanciones ambulatorias (como la libertad asistida, servicios en beneficio a la comunidad, salida alternativa y reparación del daño) son administradas por organizaciones privadas sin fines de lucro que son supervisadas y financiadas por Sename según la Ley № 20.032.

4 Convención sobre los Derechos del Niño/a, 1989; Las Reglas de Beijing, 1985; Directrices de Riad, 1990; Reglas de La Habana, 1990; Reglas de Viena, 1997).
} 
e internacionales, ${ }^{5}$ establece la "necesidad de avanzar en la generación de nuevas opciones de justicia, como por ejemplo, la justicia restaurativa" (CHILE, 2016, p. 13), enfocándose en la reparación del daño, las necesidades y los derechos de las víctimas de delitos.

En general, las practicas restaurativas en el país son escasas, de las cuales la mediación se destaca y, si bien estuvo originalmente relacionada a la esfera civil y comunitaria, viene ganando espacio en la penal, caminando hacia las concepciones propias de la JR (DÍAZ, 2010; DÍAZ; NAVARRO, 2015). Sobre la implementación de la mediación penal propiamente, desde el año 2000 fueron al menos 20 iniciativas desarrolladas en Chile, las cuales en su mayoría se dieron en el contexto de justicia de adultos, con poca sistematización y evaluación, y utilizaban protocolos de otras realidades legislativas o adecuando metodologías utilizadas en la mediación familiar (regulada legalmente en Chile) (DÍAZ; NAVARRO, 2015; GONZÁLEZ; FUENTEALBA, 2013).

La primera experiencia sistematizada de mediación penal juvenil en el país es el denominado Estudio Práctico (EP en adelante). El Ministerio de la Justicia y Derechos Humanos (MJYDH), frente a la necesidad de (1) analizar la posibilidad específica de incluir procesos de mediación penal para jóvenes infractores y (2) definir criterios y metodologías para la incorporación de un futuro Programa Nacional de Mediación Penal Juvenil dentro del contexto de las reformas a la LRPA en el nuevo SNRSJ, decidió ejecutar una experiencia piloto de mediación penal en el contexto penal juvenil. El EP fue puesto en práctica en enero de 2017 y hasta la presente fecha de realización está aún en funcionamiento. Para materializar la derivación de casos a la mediación penal juvenil y EP, el Ministerio Público, la Defensoría Penal Pública y el MJYDH firmaron un Convenio de Colaboración que, además de unir criterios para la ejecución de la experiencia, viabiliza la iniciativa por lograr vincular simbolicamente a las máximas autoridades de las instituciones, siendo la primera vez que se hace un Convenio con estas características en Chile. Ese documento tiene especial relevancia ya que el país aún carece de ley expresa para respaldar las prácticas de JR, fomentando la internalización del tema entre los operados, de sus principios, estándares y buenas prácticas.

En concreto, el EP, además de cuidar en resguardar los principios de la JR, responde a enseñanzas dejadas por experiencias anteriores implementadas en el país (DÍAZ; NAVARRO, 2015):

- Establece una buena coordinación entre los actores involucrados, garantizando la participación activa de las instituciones (Ministerio Publico y Defensoría Penal Pública, sobre la gestión del MJYDH), la confianza y el compromiso entre los actores involucrados de todos los niveles.

- Promueve un estudio que ofrece asesoría, capacitación a los actores, y además evalúa su primer año de implementación, con espacio para corregir debilidades durante ese proceso. ${ }^{6}$

- Diseño e implementar buenos protocolos de actuación entre los centros de mediación y el Ministerio Publico, asegurando la derivación de casos y relación directa y rápida entre las instituciones.

- Criterios de derivación definidos y que consideran, por primera vez, la accesibilidad de casos con mayor relevancia jurídica (experiencias anteriores la derivación de casos fue incipiente y esporádica, y en su mayoría delitos de bagatela, principalmente en delitos de orden patrimonial)

- Considera la participación del entorno social, la familia y la sociedad civil, y principalmente considera la relevancia de la víctima y su red de apoyo en el proceso

Si bien durante su primer año su implementación si dio específicamente en la ciudad de Santiago, región metropolitana de Chile, objetivamente casos tratados en la Fiscalía Regional Centro Norte, actualmente fue expandida y también está siendo implementada en otras ciudades del país (en Valparaíso y La Serena). Esa expansión se dio como respuesta a los resultados positivos del proyecto, el cual también sirvió como antecedente importante para la propuesta de un futuro Programa de Mediación Penal Juvenil en el marco del nuevo Servicio Nacional de Reinserción Social, actualmente en tramitación en el congreso.

\footnotetext{
5 Ver, por ejemplo, la Directiva 2012/29/EU, promulgada por la Unión Europea y ONU (1985).

6 Informe Final "Capacitación, Asesoría y Estudio de un Programa Piloto de Mediación Penal Juvenil". Departamento de Psicología, Universidad de Chile. Financiamiento: Ministerio de Justicia y Derechos Humanos, Gobierno de Chile, 2017.
} 


\section{BRASIL Y CHILE JUNTOS EN LA JUSTICIA JUVENIL: POSIBLES DIÁLOGOS}

Demonstrar el estado de desarrollo diferente en materia de JRJ en cada país, con contextos socioculturales diversos, permite el desarrollo de un estudio comparado potencialmente relevante, donde es posible observar similitudes y diferencias. Esa metodología es especialmente relevante en el continente Latinoamericano donde, a pesar del avance de la diseminación de las practicas restaurativas, esas tienen sido poco sistematizadas y hay una carencia de un mayor intercambio y asistencia mutua de información entre esos países para lograr un mejor desarrollo de eses servicios. Los datos recolectados sobre las experiencias en Brasil y en Chile logran mostrar que las practicas restaurativas en esos países siguen escasas a pesar de la disponibilidad y, en general, se observa en ambos que aún se hace necesario (1) definiciones más claras, específicamente de JR, y (2) generar evidencias en el sentido de desarrollar sus principios, identificar/ definir las buenas prácticas y gestionar capacitaciones profesionales para la calidad de las iniciativas.

En Chile, es importante ratificar que el país vive un importante momento de rediseño y nuevo enfoque en el entendimiento e intervención de los conflictos que involucra jóvenes, donde la experiencia piloto del EP cumple un rol fundamental en ese proceso y es un antecedente fundamental para él un futuro Programa de Mediación Penal Juvenil en el país. Es interesante observar que la experiencia de implementación da JRJ en Chile vivió un progreso consciente de su modelo, acerca la pertinente y la metodología a ser aplicada en el país, que culmino en lo que hoy es el EP. En ese sentido, abordando todos los aprendizajes de experiencias anteriores, el EP logra traer antecedentes más claros y realistas sobre la JRJ en Chile y, además, cumple un rol fundamental para resguardar los impactos positivos del enfoque.

En concreto, entendiendo el momento estratégico de Chile, ese artículo tiene el propósito de garantizar que eses espacios no sean colonizadas por otras prácticas ya enraizadas en el sistema de justicia tradicional, como espacios desprestigiados de igual reproducción de la lógica vigente, con el riesgo de perder las propuestas innovadoras de la JR. En ese sentido, observar la experiencia de Brasil se hace fundamental para buscar referencias positivas, pero también los desafíos que se debe prevenir.

Con la ratificación y vigencia en Brasil de la Convención sobre los Derechos del Niño, Niña y Adolescente en 1990, el 38/5000 y el Estatuto del Niño y del Adolescente (ECA) - no. 8.069/90, es el principal avance a nivel legislativo en el contexto de la justicia juvenil nacional, aplica para todos los adolescentes entre 12 y 18 años que han cometido un ato infracional, 192/5000 conforme a lo dispuesto en los artículos 103, 104 y 112 de la legislación estatutaria en combinación con la Ley del Sinase que se ocupa de la política socioeducativa dirigida a los adolescentes que cometen una infracción.

En ese sentido, el enfoque de la intervención es la responsabilización de los adolescentes que cometen ato infracional, la reinserción social y la prevención de la reincidencia, incorporando nuevas estrategias de "diversificación" de las respuestas estatales como las salidas alternativas, y también a través de sanciones no privativas en el Estatuto del Niño y del Adolescente y en la política socioeducativa del Sinase.

En concreto, el análisis acerca la implementación de la ley no ha sido positiva, apuntando al no cumplimento de su objetivo y la inefectividad de ciertas medidas socioeducativas ${ }^{7}$ centrándose más en la individualización de la culpa y se distanciando carácter restaurativo, mismo previsto en la Ley del Sinase.

Con respecto a la Política de Infancia adoptada por el Estado brasileño, la política es completa y consolidada, ya que prevé la protección de los derechos y garantías de los niños y adolescentes, como víctimas cuando el País viola o ignora sus derechos y garantías fundamentales.

Una política consistente de reinserción social y un servicio descentralizado, que contempla un modelo de intervención basado en los principios de la Justicia Restaurativa (JR), entre otras perspectivas teóricas, entretanto, no y propone la creación de un Programa de política socioeducativa restaurativa como medida de diversificación y nueva vía de alternatividad al proceso, proyectando una mejora y además está en consonancia con la Política Nacional de Víctimas que, respondiendo a normativas regionales e internacionales, establece la "necesidad de avanzar en la generación de nuevas opciones de justicia, como por ejemplo, la justicia restaurativa" (CHILE, 2016, p. 13), enfocándose en la reparación del daño, las necesidades y los derechos de las

En Brasil, el Estatuto del Niño y del Adolescente no habla de sanciones para los adolescentes, sino, en medidas socioeducativas 
víctimas de delitos. Existe una propuesta para un programa de Justicia Restaurativa en Brasil, no solo para la justicia juvenil, sino para otras áreas especializadas: como el Tribunal de Ejecuciones, la Familia, entre otras. Demostrando su diversidad y elasticidad de apalancamiento en otros espacios.

En el caso de Brasil, se observa que las principales barreras sociales, políticas e institucionales están vinculadas a las raíces culturales brasileñas, especialmente la percepción y confrontación de conflictos, luchando por la judicialización. Además de la cultura jurídica, existe la necesidad de fortalecer la educación jurídica de las universidades sobre otras formas alternativas y apropiadas para pacificar los conflictos; no exclusivamente el Poder Judicial. Significa la humanización de los cursos de derecho, empoderando al abogado de manera restaurativa. En Brasil, la investigación sobre la justicia restaurativa aún necesita ser fortalecida; No se ve en Brasil solo como una técnica o metodología, sino como una ruptura de paradigma que enfrenta problemas de justicia social, que involucran género, raza y desigualdad social.

Los puntos fuertes en el proceso de implementación de prácticas restaurativas son en su mayoría fomentados y articulados por el poder judicial. Si bien el país cuenta con un marco legal y de protección, no existe una sistematización de los procedimientos ni un fortalecimiento continuo e institucional de las prácticas restaurativas. Sin embargo, es posible observar algunas características sobre la Justicia Restaurativa en Brasil.

En este entorno, la Justicia Restaurativa en Brasil, especialmente diseñada y aplicada en el sistema penal juvenil, es multifacética y se lleva a cabo en diversas comunidades y espacios con el poder judicial, los fiscales y la sociedad civil. Ella no exige exclusivamente la justicia juvenil, también se encuentra en otras áreas, como el Tribunal de Violencia Doméstica e Intrafamiliar y el Tribunal Penal. Aunque existe una Resolución CNJ para estandarizarlo como técnica o metodología, se aplica de varias maneras, a pesar de que predominan los círculos de consolidación de la paz de Kay Pranis. Su objetivo es respetar la participación de los involucrados (víctima, delincuente y la comunidad) en las prácticas, así como el principio de empoderar a los ciudadanos.

Brasil atraviesa el momento de transición y crisis institucional en relación con el papel del poder judicial como promotor de prácticas restaurativas en el sistema juvenil. Tiene un marco teórico y legal que es el Estatuto de Niños y Adolescentes y la Ley del Sinase, pero dificulta la operacionalización de las prácticas. Debido a su dimensión espacial, territorial y cultural, no tiene una sistematización o estandarización de la práctica, aunque el Consejo Nacional de Justicia a través de la Resolución 225/16 tiene como objetivo sistematizar o estandarizar las prácticas a través del poder judicial; que de alguna manera tiene efectos negativos, uno de los cuales es monopolizar la justicia restaurativa y recaudar recursos humanos voluntarios no remunerados para llevar a cabo prácticas restaurativas.

Aunque varios tribunales especializados en menores y jóvenes han firmado un acuerdo de cooperación para trabajar con la Justicia Restaurativa en la atención social y educativa para adolescentes; Todavía no se incorpora la política judicial en la rutina institucionalizada del sistema juvenil. Cada unidad que se adhirió voluntariamente a la propuesta, incluso con respecto a la estandarización de la Resolución 225/16 de CNJ; no sigue continuamente el déficit estructural y humano dentro de los palos para hacer el trabajo. Continúa en el país a través de CNJ y un organismo de administración de Justicia Restaurativa en Brasil, sensibilización, capacitación para acercarse a la sociedad civil, atrayendo personas voluntarias que pueden agregar y unirse a la causa restaurativa.

Sin embargo, uno de los programas de justicia restaurativa considerados completos en los tiempos contemporáneos es la política municipal e interinstitucional en Caxias do Sul-RS, que es una asociación entre el poder judicial, las autoridades públicas (el municipio) y la sociedad civil. La política pública restaurativa de Caxias do Sul incluye la atención en la comunidad y el poder judicial, destacando uno de los centros de atención para niños y adolescentes. Lo interesante de la propuesta interinstitucional es que personas calificadas, algunas trabajan voluntariamente y otras, son contratadas por las autoridades públicas o se inclinan a la función del núcleo que recibe del municipio para tal fin. Lo que debe ser positivo. Y así motiva a las personas a calificar y ser reconocidas para el trabajo social.

Debido a esto, una de las críticas a los procesos de implementación de la Justicia Restaurativa en Brasil es la búsqueda de personas que después de la capacitación, algunas gratuitas y otras remuneradas, trabajarán voluntariamente. Lo que causa preocupación: si la política restaurativa es realmente importante para el sistema juvenil, ¿por qué no valorar a los profesionales calificados y calificados para realizar prácticas restaurativas? 
En cualquier caso, la Resolución CNJ no 225 aporta dos fundamentos importantes para la Justicia Restaurativa brasileña: 1) establece principios y pautas de flujo mínimo para la justicia restaurativa a fin de definir su identidad y alentar a los jueces a implementarla, y al mismo tiempo, para evitar desviaciones, pero lo suficientemente abierto para que se respeten las diversas metodologías, sin incluirlo en un solo modelo cerrado; 2) mantiene la comprensión de la Justicia Restaurativa, no como una técnica de resolución de conflictos, a pesar de contener una gama de ellos, sino como un verdadero cambio en los paradigmas de la convivencia, con el objetivo de crear conciencia sobre los factores relacionales, institucionales y sociales que motivan la violencia y la violencia. de transgresión, para involucrar a todos los miembros de la sociedad como protagonistas en la transformación hacia una sociedad más justa y humana; y 3) aunque se centró en el alcance del Poder Judicial, dados los límites de las atribuciones y la competencia normativa del CNJ, la Resolución buscó enfatizar que la Justicia Restaurativa no es exclusiva de los Tribunales, sino la redención del valor de la justicia en el conjunto por lo tanto, la responsabilidad de las personas, las comunidades, la sociedad civil organizada, el poder judicial y otros miembros del poder público.

Sin embargo, el papel de gerente y promotor de la Justicia Restaurativa no es simple debido a la cultura legal brasileña, que aún reconoce en el poder judicial el tercero, extraño y necesario para resolver sus conflictos. El Estado a través del poder judicial no quiere eludir sus responsabilidades, incluyendo: la protección total de niños, niñas y adolescentes. Es inconcebible devolver el conflicto a la sociedad cuando históricamente se convirtió en el titular o monopolizó el conflicto. Se espera que el Estado actúe como facilitador y socio de la sociedad, no solo mediante la elaboración de políticas públicas protectoras para niños y adolescentes, sino también como el responsable de su ejecución y eficacia.

\section{CONCLUSIONES}

En ese sentido, conocer la experiencia de Brasil y Chile (considerando las fortalezas y los desafíos), abre un espacio importante de aprendizajes para aquellos contextos en que la implementación de las practicas restaurativas aún están en una etapa temprano de implementación, como Chile, pero también ayuda a visualizar con mayor claridad elementos que deben ser revisados en países con experiencia más avanzada, como propiamente Brasil.

Desde el nivel de las políticas públicas sobre la infancia, se observa que ambos países tienen debilidades significativas en la impugnación de las recomendaciones internacionales que ratifican el enfoque de los resultados, existe una escasez de espacios de participación más amplios por parte de estos actores, que se limitan a la asistencia y carácter tutelar, como objetos necesitados y bien nada capacidades de resocialización. Por otro lado, fortalece la necesidad de difundir las prácticas restaurativas en el contexto de la infancia, y puede presentarse a los jóvenes en situación de victimización, testamento o delincuente, y promoverse en todas las etapas del proceso de justicia penal.

La JR como un concepto que está en constante evolución: entendiendo la JR como un enfoque que lida con conflictos sociales (más que con actos criminales), con una noción amplia de justicia (que permite identificar "elementos de justicia" en prácticas más informales), se considera que tiene un concepto que por esencial esta siempre en evolución. Poner la mirada en las experiencias de esos dos países latinoamericanos se hace fundamental para la búsqueda de un desarrollo de calidad de prácticas restaurativas en la región, ya que se tensiona la necesidad de analizar el conflicto dentro de su contexto social, aumentando la complejidad del fenómeno (al contrario de los procedimientos del sistema de justicia tradicional), para poder disponer así de reales herramientas de transformación (en lugar de simplemente restaurar el statu quo).

En este contexto, el estudio tuvo como problema de investigación: ¿cuáles son los procesos sociales, políticos y económicos que facilitan y/u obstaculizan la implementación de prácticas de justicia restaurativa juvenil en Brasil y Chile como políticas públicas que forman parte del sistema de justicia? Al analizar las dos experiencias con la Justicia Restaurativa en ambos países latinoamericanos, uno puede notar la dificultad de aproximar las diferentes realidades con la implementación de prácticas de Justicia Restaurativa en el sistema juvenil, debido a varias características planteadas anteriormente en el texto.

Aunque Brasil tiene una legislación protectora para niños y adolescentes, así como su propia legislación para la política socioeducativa que puede abarcar prácticas restaurativas para adolescentes involucrados en el delito; Los problemas derivados de la cultura jurídica y la desigualdad social debilitan los principios de auto- 
nomía y la participación de los adolescentes, las víctimas y la comunidad. Sin embargo, la diversidad espacial-territorial brasileña y el sentido de pertenencia en algunas comunidades, en asociación con el estado y otros movimientos sociales, pueden convertirse en un medio de prevención, protección y garantía de los derechos fundamentales de los adolescentes que necesitan atención y cuidado tanto de la sociedad como del sistema de justicia.

Por otro lado, la experiencia chilena también puede contribuir a Brasil, en términos de construir una práctica restaurativa dentro de la política de reintegración social de la protección de los adolescentes, por mencionar: la mediación criminal como una técnica de resolución de conflictos distinta del círculo de construcción de la paz. En resumen, ambos países deben priorizar las políticas públicas para niños y adolescentes, prestando atención a un sistema de justicia juvenil que respete las convenciones y normas internacionales centradas en el área de la infancia y la juventud.

Mismo que Brasil y Chile tienen sistemas jurídicos e instituciones jurídicas algo sólidos, la aplicación de la Justicia Restaurativa debe concebirse y analizarse como una posibilidad de modernizar la comprensión y las formas de abordar los conflictos. Por lo tanto, ambos pueden considerarse en la etapa de identificación de las mejores metodologías e incluso con la creación de sus propias metodologías, de acuerdo con sus realidades y necesidades.

\section{REFERENCIAS}

ACHUTTI, D.; LEAL, M. A. S. Justiça Restaurativa no Centro judiciário de Solução de Conflitos e Cidadania: da teoria à prática. Revista de Criminologia e Políticas Criminais, Maranhão, v. 3, n. 2, p. 84-100, jul./dez. 2017.

ACHUTTI, D.; PALLAMOLLA, R. Levando a Justiça Restaurativa à sério: análise crítica de julgados do Tribunal de Justiça do Rio Grande do Sul. Redes: Revista Eletrônica Direito e Sociedade, Canoas, v. 5, n. 2, p. 279-289, nov. 2017.

BERRÍOS, G. La ley de responsabilidad penal del adolescente como sistema de justicia: análisis y propuestas. Revista Política criminal, Chile, v. 6, n. 11, 163-191, 2011.

BOLÍVAR, D. et al. Estudio proyecto capacitación, asesoría y estudio práctico mediación penal juvenil. Informe Final. Santiago: Facultad de Ciencias Sociales; Universidad de Chile, 2017.

BRASIL. Relatório analítico propositivo justiça pesquisa direitos e garantias fundamentais: pilotando a justiça restaurativa: o papel do Poder Judiciário. Conselho Nacional de Justiça. 2019. Disponível em: http://www.cnj.jus.br/files/conteudo/arquivo/2018/06/48a-1d20e9350d40373889719054070b0.pdf. Acesso em: 1 jul. 2019.

BUCCI, Maria Paula Dallari. Políticas públicas: reflexões sobre o conceito jurídico. São Paulo: Saraiva, 2006.

CHILE. Boletín No 11174-07/2017. Proyecto de Ley que crea el Servicio Nacional de Reinserción Social Juvenil e introduce modificaciones a la ley N. 20.084, sobre responsabilidad penal de adolescentes, y a otras normas que indica, Chile: Cámara de Diputados de Chile, 2017.

CHILE. Boletín N. 1.555-14. Comisión de Constitución, Legislación, Justicia y Reglamento del Senado. Santiago, 2012.

CHILE. Subsecretaría Prevención del Delito. Política Nacional de Victimas de Delito. Gobierno de Chile, Ministerio del Interior y Seguridad Publica. 2016. Disponível em: http://www.apoyovictimas.cl/media/2016/05/Politica-Nacional-de-Victimas.pdf. Acesso em: 19 nov. 2019.

COSTA, Daniela Carvalho Almeida da. Monitoramento da justiça restaurativa em três dimensões. São Cristóvão: Editora UFS, 2019.

DE LA MAZA, C. Derechos humanos de la infancia y adolescencia: adolescentes Infractores frente a sanciones no privativas de libertad. In: VIAL, T.; MISSANA, S. (org.). Informe anual sobre derechos humanos en Chile. Santiago: Ediciones Universidad Diego Portales, 2013. p. 165-186.

DÍAZ, A. La experiencia de la mediación penal en Chile. Revista Política Criminal, Chile, v. 5, n. 9, p. 1-67, 2010.

DIAZ, A; NAVARRO, I. Informe sobre Experiencias Nacionales de Mediación Penal y Justicia Restaurativa en Chile. Ministerio de Justicia de Chile, Santiago. Documento interno, 2015.

DUNKEL, F.; HORSFIELD, P.; PAROSANU, A. (orgs). Research and selection of the most effective juvenile restorative justice practices in Europe: snapshots from 28 EU Member States. Belgium: International Juvenile Justice Observatory, 2015.

FLORES, A. P.; ROLIANO, M. G. O programa Justiça Restaurativa do Estado do Rio Grande do Sul: um ponto de partida ou de chegada? 2016. Disponível em: https://pitangui.uepg.br/eventos/justicarestaurativa/ANAIS2016.php. Acesso em: 8 nov. 2019. GONZÁLEZ, I.; FUENTEALBA, M. Mediación penal como mecanismo de justicia restaurativa en Chile. Revista Chilena de Derecho y Ciencia Política, Santiago, n. 4, v. 3, p. 175-210, 2013. 
MELO NETO, Carlos Roberto Cals de. Por uma hermenêutica restaurativa: sistema socioeducativo, lacunas normativas e crise de interpretação do ECA. 2019. 243 f. Dissertação (Mestrado em Direito) - Faculdade de Direito, Programa de Pós-Graduação em Direito, Universidade Federal do Ceará, Fortaleza, 2019.

MIRANDA, P. et al. Elaboración de un Sistema de Supervisión para la Mediación Penal en el Marco del Nuevo Servicio de Reinserción Social Juvenil. Santiago, Chile, Ministerio de Justicia y Derechos Humanos de Chile, Documento interno, 2018.

OCDE. Comité Evaluación de la Ley OCDE. Informe Ejecutivo Evaluación de la Ley n. 20.084 que establece un sistema de responsabilidad de los adolescentes por infracciones a la ley penal. Cámara de Diputados de Chile, 2015.

ONU. Manual sobre Programa de Justicia Restaurativa. Oficina de las Naciones Unidas Contra la Droga y el Delito. Nueva York: ONU, 2006.

PRANIS, Kay. Processos circulares. São Paulo: Palas Athena, 2010.

RAMIDOFF, Marcio Luz. Sinase - Sistema Nacional de Atendimento Socioeducativo à Lei 12.594, de 18 de janeiro de 2012 . São Paulo: Saraiva, 2012.

REYES, C.; LABRENZ, C. A.; DONOSO, G. Justicia Restaurativa en Sistemas de Justicia Penal Juvenil Comparado: Suecia, Inglaterra, Italia y Chile. Revista Política Criminal, Santiago, v. 13, n. 25, p. 626-649, 2018.

SCHMIDT, João Pedro. Para entender as políticas públicas: aspectos conceituais e metodológicos. In: REIS, J. R.; LEAL, R. G. (org.). Direitos sociais e políticas públicas: desafios contemporâneos. Santa Cruz do Sul: Edunisc, 2008.

UNICEF. United Nations International Children's Emergency Fund. Agenda de Infancia 2018-2021: desafíos en un área clave en el país. 2017. Disponível em: http://unicef.cl/web/wp-content/uploads/2017/01/Agenda-Infancia-2018-2012-WEB.pdf. Acesso em 28 set. 2019.

ZEHR, Howard. Trocando as lentes: um novo foco sobre o crime e a justiça. São Paulo: Palas Athena, 2008. 